\title{
The perception of first and second pain as a function of psychological set
}

\author{
JAMES J. BARRELL \\ University of Florida, Gaine sville, Florida 32601 \\ and \\ DONALD D. PRICE \\ National Institute of Dental Research, Bethesda, Maryland 20014
}

\begin{abstract}
The effects of psychological set on perception of first and second pain were determined for 20 subjects. Percutaneous electrical shock intensities (6-8 $\mathrm{mA}, 3 \mathrm{msec})$ sufficient to evoke double pain responses were used in all subjects. Psychological sets included PAST ("Place yourself in a previous experience that was free of any significant emotional tone"), PRESENT ("Feel your foot that will be shocked"), and FUTURE ("Think to yourself that you are about to be shocked"). Perception of second pain was never perceived in PAST and FUTURE sets but was always perceived in the PRESENT set. Furthermore, at minimal rates of stimulation $(>1 / 3 \mathrm{sec})$, summation of second pain occurred in the PRESENT set but not in the FUTURE set. All subjects startled in the FUTURE set and did not startle in PAST or PRESENT sets. Each subject reported that the aversiveness of the shock related to painful sensations in PAST and PRESENT sets and to ones own body responses in the FUTURE set.
\end{abstract}

In the early part of this century, Head (1920) concluded that the skin was served by epicritic and protopathic afferent systems in which each gave rise to its own particular types of sensations. Epicritic sensations were considered to be accurately localized, to not outlast the stimulus, and to provide qualitative information about the stimulus. Thus, epicritic pain can be elicited by mild pricking of the skin with a needle. In contrast, protopathic pain is less well locilized, slow in onset, often outlasts the stimulus, and summates with its repeated application (Head, 1920). Many protopathic pains are difficult to endure and contain special feelings of unpleasantness or "feeling tone" (Head, 1920; Sinclair, 1967).

A simplitied demonstration of the two types of pain can be made when a synchronous noxious stimulus is applied to the distal portion of an extremity. When this is done, the experience is often a sharp first pain followed by a second burning or throbbing pain about $.5-1.0 \mathrm{sec}$ later. This second pain increases both in intensity and duration if the stimulus is applied at a frequency greater than once every $3 \mathrm{sec}$ (Price, 1972). This summation of second pain is a psychophysical parallel of responses of dorsal horn sensory transmission cells to repetitive $\mathrm{C}$ fiber stimulation (Price \& Wagman, 1970; Wagman \& Price, 1969). When single shocks are delivered to cutaneous $C$ fibers at frequencies greater than $0.3 / \mathrm{sec}$, the long

Address reprint requests to Donald D. Price, National Institute of Dental Research. NIH. Bldg. 30, Room B-20. Bethesda, Maryland 20014. latency discharges evoked in dorsal horn neurons become more prolonged and higher in frequency. Short-latency high-frequency responses are evoked in these same neurons by Ad fiber stimulation. Thus, first and second pain are related to conduction in Ad and $C$ fibers and to two separate integrative responses of dorsal horn cells. Therefore, epicritic and protopathic pain can, to a significant extent, be respectively related to $A d$ and $C$ fiber groups and to the central mechanisms which they activate (Bishop, 1960; Collins, Nulsen, and Randt, 1960; Head, 1920; Landau \& Bishop, 1953; Lewis \& Pochin, 1938a, b; Melzack \& Wall, 1965; Price \& Wagman, 1970; Wagman \& Price, 1969).

However, it would be a mistake to presume that all of the perceptual attributes of epicritic and protopathic pain have invariant relationships to these two functional afferent groups. The lack of such relationships is indicated by the facts that not all subjects even experience double pain and that varying degrees of affect are experienced by subjects in response to a standard noxious stimulus (Head, 1920; Jones, 1956; Lew is \& Pochin, 1938a, b; Price, 1972; Sinclair d Stokes, 1964). One possible contribution to such variability in all of these studies is the failure to control for psychological set (Sternbach, 1966). For example, the instruction given to Head and Rivers's subjects to remain passive in their observations was never checked by later asking these subjects whether this in fact was what they had done (Head, 1920). Psychological. set was only assumed to be controlled. 
The present study was undertaken to determine if and to what extent psychological set influences the experience of first and second pain. Particular attention was paid to the summating and aversive aspects of pain. since these characteristics seems to vary within and across subjects.

\section{METHODS}

The subjects were 20 paid volunteers from the university campus (10 males and 10 females) between the ages of 18 and 26 years. All subjects were naive with respect ao any of the hypotheses to be tested. Each subject was seated comfortably in a chair. Two Grass Gold cup electrodes were fastened over the medial malleolus of the left foot and were separated by $1.5 \mathrm{~cm}$. Significant fluctuations in basal skin resistance were abolished through careful application of Sanborn redux electrode creme and by continuous monitoring of skin resistance throughout the experiment. Skin resistances varied between 10 and $15 \mathrm{k} \Omega$ across subjects and varied less than $1 \mathrm{k} \Omega$ during a session for any given subject. A constant current stimulator was used to delivered 3-msec-duration square-wave pulses, whose intensity was increased in $1-\mathrm{mA}$ increments to a point where a single shock evoked both an initial pricking and a late burning sensation. This intensity ranged between 6 and $8 \mathrm{~mA}$ among subjects and was held constant throughout each experimental session.' The two pain components were easily identitied by all subjects without provocation or suggestion by the experimenter of a possible double pain. They were simply asked to attend carefully to sensations in the foot. However, once the experience of double pain was reported. these subjects then participated in one of two experiments involving effects of psychological set.

\section{Experiment 1: Effect of Psychological Set on First and Second Pain [Single Shocks]}

Each of 10 subjects was given three sets of instructions directing them into a (1) PAST. (2) PRESENT, and (3) FUTURE pscyhological set. All three conditions were randomly presented to each subject. Instruction for each set was the following: (1) PAST - "Place yourself in a previous experience that was free of any significant emotional tone," (2) PRESENT-"Place your attention in your foot which will be shocked. Feel it. Do not think about it or visualize it," and (3) FUTURE-"Repeatedly think to yourself that you are about to be shocked." All subjects were instructed to close their eyes during each set. Practice was allowed in those instances where the subject had difficulty getting into the set.

Verbal reports. obtained after a single shock during each set (three shocks per subject), consisted of answers to the following questions: (1) "What was your context (set) just prior to stimulation?" (2) "What did the stimulation feel like?" (3) "Was the stimulation painful?" (4) "How much of your body responded to the stimulation?" The last question was corroborated by observations of the subject by both investigators.

\section{Experiment 2: Effect of Psychological Set on Perception of Summation Second Pain}

The effects of both FUTURE and PRESENT psychological set on the progressive increase in second pain were tested in 10 subjects not used in the preceding experiment. Four trains of $6-8$ shocks were delivered whose frequency of stimulation was fixed at $0.3 / \mathrm{sec}$, $0.5 / \mathrm{sec}, 0.75 / \mathrm{sec}$. or $1 / \mathrm{sec}$. These different frequency shock trains were presented in random order. After each train of shocks, the subject was asked if each successive shock felt less intense, the same, more intense, or changed in any way. These tests were done under PRESENT and FUTURE psychological sets presented in random order.

\section{Reaction Time Measurements}

It was important to confirm that the long-latency burning sensations evoked by our stimulation procedure were related to impulses conducted in unmyelinated fibers. Reaction times to first and second pain were determined in six subjects by recording the stimulus artifact and leverpress on a polygraph. The intervals between shocks varied randomly between 3 and $5 \mathrm{sec}$. Reaction times ranged from 220 to $271 \mathrm{msec}$ for first pain and from 1.4 to $2.2 \mathrm{sec}$ for second pain. Conduction velocities of impulses related to second pain were then calculated by dividing the distance from the foot to the L-S spinal segment by the difference in reaction times to first and second pain. The conduction velocities of impulses related to second pain were determined to be between 0.8 and $1.6 \mathrm{~m} / \mathrm{sec}$ with a mean of $1.3 \mathrm{~m} / \mathrm{sec}$ ( $\mathrm{six}$ subjects, 90 determinations), values which are consistent with known conduction velocities of $C$ fibers and with previous results (Lewis \& Pochin, 1938a, b; Price, 1972; Sinclair \& Stokes, 1964).

\section{RESULTS}

\section{Experiment 1}

The following accounts were derived from statements made by subjects after each psychological set. The results are summarized in Table 1 .

Past set. All subjects psychologically placed themselves in a previous situation. In each case, the situation lacked any obvious emotional tone. All subjects reported a brief sharp sensation as a result of the shock and in no instance was an additional delayed burning, throbbing, or other sensation reported. In other words, double pain was not indicated by any subject. Six of the 10 subjects described the sensation as painful but certainly tolerable and 4 subjects reported the shock as not painful. Those subjects experiencing the shock as painful stated that the sensation itself was painful. In all cases, neither did the subject experience any body response (i.e., foot jerk or startle) nor was any body response observed by the investigators.

Present set. All subjects reported that they experienced feelings in the foot just prior to stimulation. Five of the subjects reported the stimulus as penetrating, and all 10 subjects described two components, an early sharpness $(7$ subjects) or "grabbing" ( 3 subjects) and a later burn or throbbing that occurred about a second or more after the first component. Nine out of 10 subjects described the

Table 1

Psychological Set and Pain Perception

\begin{tabular}{lccc}
\hline & \multicolumn{3}{c}{ Number of Subjects } \\
$\begin{array}{c}\text { Psycholog- } \\
\text { ical Set }\end{array}$ & $\begin{array}{c}\text { Reporting } \\
\text { Shock as } \\
\text { Painful }\end{array}$ & $\begin{array}{c}\text { Reporting } \\
\text { Delayed } \\
\text { Sensations* }\end{array}$ & $\begin{array}{c}\text { Showing } \\
\text { Startle } \\
\text { Response }\end{array}$ \\
\hline Past & 6 & 0 & 0 \\
Present & 9 & 10 & 0 \\
Future & 10 & 0 & 10 \\
\hline
\end{tabular}

*Second pain 
shock as painful and/or noxious. When asked what was noxious about the stimulation, the 9 subjects referred to the feeling or sensation elicited. No one considered a body response part of the painful experience, although all subjects reported and exhibited a very localized body response to the stimulation (i.e., foot jerk). This response was corroborated in each instance by the investigators.

Future set. All subjects reported that they were waiting for the shock to come. One subject reported the sensation as cone shaped, another as a grabbing sensation, and the remaining subjects perceived the stimulus but were unable to describe the quality of the sensation. No subject experienced a later burning or throbbing sensation. All subjects reported the experience as painful and/or noxious, but indicated that they reacted to the stimulus rather than clearly perceived the sensations. Each subject definitely startled in response to the shock and independently concluded that this reaction or whole body response was a major source of the disagreeableness of the experience.

\section{Experiment 2: Effect of Psychological Set on Summation of Second Pain}

When placed in the PRESENT set, all 10 subjects reported a double pain to each shock when these shocks were delivered once every $3 \mathrm{sec}$. At this frequency, no subject indicated either a progressive increase or decrease in the intensity of second pain. However, with higher shock frequencies $(.5 / \mathrm{sec}$, $.75 / \mathrm{sec}$, and $1.0 / \mathrm{sec})$, definite increases occurred in intensity of second pain with each successive shock (Table 2). However, first pain was not perceived as increasing or decreasing during any of these shock trains. These findings were consistent among all 10 subjects. When these same subjects were placed in the FUTURE set, no subject reported double pain (Table 2). Furthermore, when shocks were delivered at frequencies that during the PRESENT set produced summation of second pain, no such progressive increase occurred in any subject, nor was second pain ever experienced. As in the first experiment, subjects startled in response to most, if not all, shocks.

\section{DISCUSSION}

It is clear that psychological set markedly influcnces both perception of pain and the motor response to a sudden noxious stimulus. Thus, in the present study, the likelihood that an intense shock was perecived as painful was less in an affectively neutral PAS'l set and more in the PRESENT and FU'TURE sets. Furthermore, the perception of second pain was absent in PAST and FUTURE sets and always oceurred in the PRESEN'T set. An initial pain
Table 2

\begin{tabular}{crrrr} 
Number & \multicolumn{5}{c}{$\begin{array}{c}\text { Subjects } \\
\text { Increase }\end{array}$ in Second Pain } \\
\hline Psycholog- & \multicolumn{5}{c}{$\begin{array}{c}\text { Stimulus Frequency } \\
\text { ical Set }\end{array}$} & $.3 / \mathrm{Sec}$ & $.5 / \mathrm{sec}$ & $.75 / \mathrm{Sec}$ & $1.07 / \mathrm{Sec}$ \\
\hline Present & $0 / 10$ & $10 / 10$ & $10 / 10$ & $10 / 10$ \\
Future & $0 / 10$ & $0 / 10$ & $0 / 10$ & $0 / 10$ \\
\hline
\end{tabular}

Was perceived in all sets. In this respect, second pain is more labile than first pain, in that it can be selectively inhibited by particular psychological sets and, as shown in a previous study, by certain peripheral stimuli (Price, 1972). Moreover, at minimal stimulation frequencies, summation of second pain always occurred in subjects in the PRESENT set but never occurred during the FUTURE set. With a FUTURE set, the second component not only failed to grow in perceived intensity, but was absent from the entire experience. The extent to which second pain depends on psychological set may partly account for earlier reports on the variable nature of second pain as well as the controversy surrounding its existence (Jones. 1956: Sinclair, 1967).

When subjects were asked why the shocks were painful, the reasons differed according to psychological set. The disagreeableness or aversiveness of the shock was clearly related to the sensation in PASI and PRESENT sets and to one reaction to ones own body response in the FUTURE set. Disagreeableness or aversion is an integral component of pain (Melzack \& Wall, 1965), yet this component can be directed toward either the sensation or the body response, depending on psychological set.

Results from more recent pilot work have further supported the generality of our findings. Pain modulating effects of our three psychological sets have been independently assessed for first and second pain. Eleven subjects were used in the first and seven in the second study. For first pain, the influences of set were examined under conditions of pin prick. In contrast, second pain was selectively studied through the use of intense shocks after selective ulnar nerve blockade of afferent impulses necessary for first pain.

Irrespective of procedure, pain was reported least often in an affectively neutral PAST set when compared with FUTURE and PRESENT sets. Aversiveness of pin prick or shock was related to sensation in PAST and PRESENT sets and reaction to one's own body response in a FUTURE set. Startle responses occurred only in the FUTURE set. Before and after nerve block, characteristics of second pain (i.e., summation, burning, long durations) were always found in the PRESENT set and never in PAST or FUTURE sets. Although sensations were reported for PAST and FUTURE sets following nerve block, none of these reports included characteristics of 
second pain. Sensations were reported as brief and often "sharp" or "grabbing. " The above pilot results are consistent with those reported in the present study. All of our findings suggest that one cannot understand the experience of even a simple painful stimulus without considering the psychological context under which a nociceptive stimulus is presented.

\section{REFERENCES}

Bishop. G. H. The relation of nerve fiber size to modality of sensition. In W. Montagna (Ed.). Adrances in biology of skin. (Vol. 1) Cutaneous innervation. New York: Pergamon: 1960, Pp. 88-98.

Collins, W. F., Nulsen, F. E., \& Randt, C. T. Relation of peripheral nerve fiber size and sensation in man. Archives of Nelurology, 1960, 3, 381-385.

HEAD, H. Studies in neurology. London: Oxford University Press, 1920.

Jones, M. H. Second pain: Fact or artifact? Science, 1956, 126. $442-443$.

LANDAU, W.. \& Bishop. G. H. Pain from dermal, periosteal, and fascial endings and from inflammation. Archives of Neurology and Psychiatry, 1953, 69, 490-504.

LEwis. T., \& Pochin, E. E. The double response of the human skin to a single stinulus. Clinical Science, 1938, 3, 67-76. (a)

LEwis. T., \& Pochin, E. E. Effects of asphyxia and pressure on sensory nerves of man. Clinical Science, 1938, 3, 142-155. (b)
Melzack, T.. \& Wall, P. D. Pain mechanisms: I new llewy Scionce, $1965,150,971-9^{7} 9$.

PRICE, D. D. Chatracteristics of second pain and flexion reflexes indicative of prolonged central summation. Experimintal Neurology', 1972, 37. 371-387.

Price, D. D., \& Wagman, 1. H. The phesiolegical roles of 1 and C fiber input to the dorsal horn of .1 . Mulatha. Experimonal Neurology. 1970, 29, 383-399.

Sinclair, D. C. Cutantotis sinsation. Lomtoti: Onforat University Press. 1967.

Sinclatr, D. C., \& Stokes, B. A. R. The prosituction and characteristics of "second pain." Brain. Journal of V'nrolugy. $1964,87,609-618$.

Sternbach, R. A. Principles of psychophysiology, New lork: Acadenic Press. 1966.

Wagman, 1. H., \& Price, D. D. Responses of dorsal horn cells of $M$. mulatta to cutaneous and sural nerve $A$ and $C$ fiber stimuli. Journal of Neurophysiology. 1969. 32. 803-81-

\section{NOTE}

1. One of us (D.P.) has previously used similar procedures and stimulus parameters to produce double pain (Price. 1972). In that study, compression of the ulnar nerve for $40 \mathrm{~min}$ resulted in an absence of initial pricking pain and persistence of the delayed $(>1 \mathrm{sec})$ burning pain, thereby demonstrating that the two pains are subserved by separate afferent groups (i.e., Ad and C).

Received for publication June 24, 1974; revision accepted September 27, 1974.) 